\title{
Self-management for people with long-term neurological
}

\section{conditions}

\section{Hema Chaplin}

Research Assistant, Centre for Lifespan and Chronic Illness Research, University of Hertfordshire, College Lane, Hatfield AL10 9AB UK

\section{Jill Hazan}

Professional Lead for Clinical Psychology, Hertfordshire Neurological Service, Hertfordshire Community NHS Trust, Jacketts Field Neurological Unit, Jacketts Field, Watford WD5 OPA UK

Patricia Wilson (corresponding author)

Senior Research Fellow, Centre for Research in Primary \& Community Care, University of Hertfordshire, College Lane, Hatfield AL10 9AB UK

Telephone: 01707286391

p.m.wilson@herts.ac.uk 


\section{Abstract}

Although English government policy has encouraged the implementation of self-management programmes in services for people with long term conditions, the evidence for their efficacy has been limited. People with long term neurological conditions utilise community based health services including community nursing, and have particular needs in regards to self-management. This article provides an overview of the evidence of the effectiveness of self-management interventions for people with long term neurological conditions, in particular those with stroke, Parkinson's Disease and Multiple Sclerosis. The current need for better interventions is highlighted, particularly the importance of providing condition-specific information and deliverance of interventions in a group setting to improve self-management outcomes. In response to previous weaknesses of selfmanagement interventions for this population, an innovative Hertfordshire Neurological Service selfmanagement programme is discussed with implications for future research described.

Key words: Self-management, long term neurological conditions, Parkinson's Disease, Multiple Sclerosis, Stroke 


\section{Introduction}

Enabling self-care and self-management for people with long term conditions (LTCs) is an underpinning principle of chronic disease management and a continuing policy aim (Department of Health 2010), with community nurses playing an important part in reaching this goal (Wilson 2005). Self-management is seen as an empowering right for individuals with LTCs as well as a way of improving health outcomes and reducing health associated costs (Wilson 2001). Promoting self-care was one of the core requirements of the National Service Framework (NSF) for LTCs (Department of Health 2005a). While the NSF is applicable to the needs of people with a broad range of LTCs, it was developed specifically for people with long term neurological conditions (LTNCS) such as Multiple Sclerosis, epilepsy, and head injuries. However, a recent audit report criticises the lack of achievement of the quality requirements of the NSF (National Audit Office 2012) and it is also suggested that people with LTNCs have often been lost or given a low priority in the plethora of generic LTC initiatives (Bernard et al. 2008). In this paper we discuss a self-management initiative specifically for people with LTNCs such as stroke, Parkinson's Disease and Multiple Sclerosis. Following an overview of the evidence of self-management interventions for people with LTNCs, we describe the programme which was developed in collaboration with service users and carers, and discuss the implications for service providers and future research.

\section{Background: Overview on evidence of Self-management interventions for people with LTNCs.}

In the United Kingdom (UK) 15 million people have at least one LTC (Department of Health 2009). For over a decade there has been a policy focus on self-management interventions, with various self-management educational programmes, such as the Expert Patient Programme (EPP: UK), widely used across various chronic conditions. However in the management of LTNCs, there is limited evidence on which educational programmes is the most effective (Coster and Norman 2009, 
Rae-Grant et al. 2011). There is also a concern that since programmes such as the EPP are largely generic in content they do not address the specific issues associated with a LTNC and additional specialised groups are often needed for discussion of condition specific complexities (Barlow et al. 2009a). There are 10 million people in the UK living with a LTNC (Neurological Commissioning Support 2011) and many of these may already have a repertoire of self-management skills specific to their condition. For example, people with Multiple Sclerosis patients often use relaxation and pacing activities throughout the day as effective self-management techniques to avoid fatigue (Barlow et al. 2009a). It has therefore been suggested that the potential to benefit from attending a lay-led generic intervention, such as the EPP, is somewhat limited for people with LTNCs (Barlow et al. 2009b). Although lay leaders are able to deliver the course content effectively through following a script, they are unable to fully answer all questions that might arise, for example, around the medical management of the condition which previous research suggests that service users often want (Barlow et al. 2009a).

Providing care for patients with LTNCs occurs very differently from the treatment of acute diseases as patients have an on-going disorder that requires monitoring and management, and health services delivery is often provided by multiple providers in different healthcare settings (RaeGrant et al. 2011). Clinical experience suggests that optimal management of such conditions requires a multidisciplinary approach, with multifactorial health plans tailored to the patient's individual needs. This is reinforced by NICE guidelines (National Institute for Health and Clinical Excellence 2006) which recommend that patients have regular access to a broad range of medical and allied health professionals (van der Marck et al. 2009). Appropriate support for patients with LTNCs can therefore be initiated through self-care programmes led by a multi-disciplinary team teaching selfmanagement skills such as problem solving, decision making, resource utilisation, formation of patient/health care provider partnerships and action taking (Lorig and Holman 2003), in areas such as nutrition and exercise as well as medication management. 
In accordance with the Department of Health (Department of Health 2005b), which states patients with LTCs need personalised care to meet their individual requirements, a number of neurological condition-specific programmes have been developed. In this article we focus purely on those related to Parkinson's Disease and Multiple Sclerosis which are the two most common progressive neurological conditions (National Audit Office 2012), and stroke which is the leading cause of adult disability with over 110,000 strokes occurring every year in England (National Audit Office 2005). Evidence of efficacy for low cost and intensity programmes has been found in stroke and Multiple Sclerosis service users. Preliminary evidence found that the use of an individualised stroke self-management intervention for four weeks ("Bridges" workbook) can lead to an improvement in self-efficacy and perceived control (Jones et al. 2009). Whilst others found that a self-care intervention for people with Multiple Sclerosis resulted in better mental health and vitality scores and patients considered help with daily activities to be less essential ( $O^{\prime}$ Hara et al. 2002); the intervention served a protective function as the control group showed a significant decrease in levels of independence whereas the intervention group maintained their levels.

A number of condition-specific self-management programmes have focused on interventions for patients with Parkinson's Disease. The EduPark patient education programme for people with Parkinson's Disease and their carers aimed to deal with psychosocial problems and an initial UK evaluation (Simons et al. 2006) found short-term positive effects on mood and favourable evaluation by participants; however no significant effects were found with regards to quality of life and depression. EduPark was also tested across seven E.U countries using purely Parkinson's Disease patients; again this found short-term mood elevation but also reduced disease-related psychosocial problems long-term (Macht et al. 2007). Therefore the EduPark appears to be an intervention that broadens patients' knowledge and establishes skills essential for self-management of Parkinson's Disease by addressing emotional and social problems and promoting activities to help deal with these condition-specific issues. The "Living Well with Parkinson's" programme found improvements 
in knowledge, psychosocial benefits of meeting others with Parkinson's Disease, new strategies and reinforcement of current strategies as a result of attending the programme (Mulligan et al. 2011).

When designing and evaluating the effectiveness of interventions for LTNCs, it is important to address the challenges of providing support for conditions that are subject to increasing deterioration in the case of Parkinson's Disease and fluctuating symptom presentation in the case of Multiple Sclerosis (Jones 2012). A systematic review found limited but promising evidence supporting the value of programmes designed to promote self-management in Multiple Sclerosis and other neurological conditions (Rae-Grant et al. 2011); therefore there is a need for well designed, condition-specific self-management programmes that covers a wide range of skill teaching using a multidisciplinary approach.

\section{The programme: How it was developed}

History of the programme

For the last ten years Hertfordshire Neurological Service had been providing condition-specific self-management groups for people with Multiple Sclerosis and Parkinson's Disease.

Various different formats, venues and times had been offered but take up and levels of satisfaction expressed by users had been disappointing.

Groups had included Getting to Grips course for people who were newly diagnosed with Multiple Sclerosis and the other groups provided by Hertfordshire Neurological Service focussed on providing key information and management advice about Multiple Sclerosis and Parkinson's Disease.

$>$ Group membership ranged from the newly diagnosed to those people who had been living with their long term condition for many years and had more progressive levels of difficulty and disability. 
There was no restriction to the number of times people could attend. Criteria for attending was not explicit and because take up and attendance was variable often groups were cancelled and rescheduled some months later which meant the flow of people through was difficult to manage.

The need for change

However feedback from users of the groups was mixed:

Some people found the groups helpful particularly the peer support aspect but the predominant theme was that people who were newly diagnosed found it very hard to be in groups with people who were further along in terms of deterioration. People found that this raised their anxiety levels and fed into their fears about the future and this issue was not acknowledged.

Other feedback suggested that the focus of the groups was around managing problems which although realistic again tended to focus attention on the negative aspects of the long term condition.

This raised the very important issue for the service about how to manage people's sense of self efficacy and expectations around their health and well-being. It seemed vital to address how people can maximise their own sense of control and feel enabled to manage their lives, through making their own choices to achieve positive outcomes. It also raised the interesting and challenging question for staff that it appeared that simply providing informative, essential and accurate information was not helping people to self-manage their condition better.

The service recognised that in the current context this programme had to be revised. One of the key issues was to identify what users and their carers would want from the programme and how to maximise attendance. At that time the service was keenly interested in Personal Health Plans (PHP) (Department of Health 2011). Previous attempts at provision of these kinds of plans were often about providing the paper work but not the opportunity to engage users in thinking about 
potential value for them. Therefore one of the challenges experienced was service users not being accustomed to debating and discussing their treatment plans and personal modifications of them as is done with PHP, so it was not as greatly received or utilised as anticipated. It was also clear that users and staff often saw the plans simply as extensions of patients' notes.

\section{Current programme}

A working group including service user representatives and partners from the neuronetwork including local branch secretaries of the Multiple Sclerosis and Parkinson's Disease Societies and the Stroke Association were involved in developing the new programme. The content is based on priorities from a service user and carer perspective, an initial generic module which provides a filter mechanism for service users who feel that a self-management approach is not for them and PHPs as a tool for self-management (Table 1). Only the first module includes both carers and service users whilst the other two modules include only service users. Although we believe it is important to offer something to carers, their presence alongside the user in the groups tended to change the agenda so the solution was to provide parallel groups for carers. However, this also raises implications in terms of resources and currently the parallel groups are not being delivered.

The modules are delivered by a multidisciplinary team including nurse specialists, physiotherapists, occupational therapists, psychologists, dieticians and rehabilitation assistants. People are offered the course soon after their referral to the Hertfordshire Neurological Service. In the case of people with stroke this is likely to be soon after diagnosis, but with people with Multiple Sclerosis and Parkinson's Disease time since diagnosis may vary. The programme is informed by two main theoretical approaches to self-management; social cognitive theory (Bandura 1986) and the self-regulation model (Leventhal et al. 2001) (Table 2). 
Module 1 - "What is self-management: pros and cons" (all conditions \& for service users and carers)

* Introduction to self-management and provision and discussion about the use of a PHP

* Agreement that if self-management is an option for the patient then active buy in to module 2 .

Module 2 - "Living Well” (all conditions \& for service users only)

* Being media savvy: Weighing up the claims about cures and treatments for long term conditions

* Relationships self-management - getting the most out of your relationships

* Core essential eating well - balanced diet

* Benefits of exercise and examples

* Living life to the full - health, roles and occupation

* Managing fatigue

* Resource Booklet - how to access support in Hertfordshire.

Module 3 - Condition specific information (for service users only)

\section{Multiple Sclerosis}

Looking after your bladder and bowel - symptoms and management

* Coping with Multiple Sclerosis -symptoms and management of changes in mood and cognition

* Keeping moving, keeping active and managing fatigue

* Recommended diet for Multiple Sclerosis

* Understanding Multiple Sclerosis - signs, symptoms and disease management

\section{Parkinson's Disease}

Understanding your condition - symptoms and management

* Exercise and physiotherapy - exercise examples 
* Cues and strategies to enhance daily function and activity

* Using Cues and Strategies for Enhancing Function and Mobility - circuits

* Medication management - symptoms and medication options

* Communication and swallowing difficulties - role of the speech therapist

Speech and Language Therapy for Parkinson's Disease - identification and advice for speech and swallowing difficulties

* Psychological aspects of Parkinson's Disease - emotions, cognitions and coping

* Nutrition - specific dietary recommendations

Taking things forward: Your personal management plan - self-management support tools

\section{Stroke}

* Eating well following stroke/TIA - dietary changes

* Stroke self-management - symptoms and management

* Speech and Language Therapy for stroke - communication and swallowing

* Stroke physiotherapy gym exercises

Psychological Aspects of Self-Management for stroke - emotions, cognitions and coping

\section{Social Cognitive Theory (SCT) (Bandura 1986)}

* One of the key predictors of behaviour change is self-efficacy which is one's belief in their ability to achieve an action.

* Self-efficacy is introduced in the first module highlighting its core importance.

* Social comparisons through group delivery can have positive effects on self-efficacy and selfmanagement.

* Setting of realistic goals and achievement of those goals is also important which is utilised in this programme through developing PHP with the patients and setting homework tasks and 
physical exercises.

Self-Regulation Model (Leventhal et al. 2001)

* Theorises how an individual understands their illness through the formation of cognitive and emotional representations and how coping strategies are developed based on an individual's perceptions.

* The programme addresses the representation, coping and appraisal stages of this model by addressing people's current illness perceptions and coping strategies, and the pros and cons of different coping techniques.

* The Service's Clinical Psychologist addresses the emotional and cognitive reactions to their neurological condition and how these change depending on a number of factors, and utilising self-management techniques, how to cope with these reactions..

\section{Service user evaluation}

The programme has been running for a year and over 300 service users have now completed it. Between July and December 2011, 160 service users attended module 1 and module 2 was completed by 60 participants. A questionnaire based process evaluation of those 60 service users who had completed the first two modules ( $100 \%$ response rate) in this period suggested that more than $80 \%$ thought they had gained what they had hoped from attending. More than $50 \%$ of patients had found discussions/other people's experiences to be the most helpful outcome of the course which reinforces the importance of the group as found by previous research (Nelson et al. 2010, Hirsche et al. 2011)(Figure 1). There was a high level of satisfaction with the programme with the only significant suggestion for change being the inclusion of partners or carers in module (25\%). 


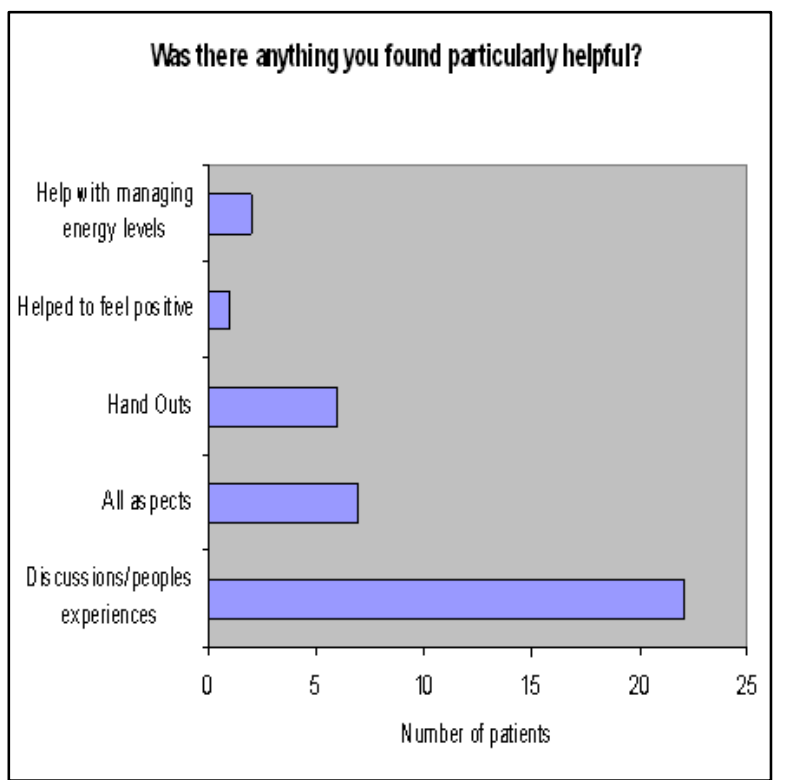

\section{Discussion}

Previous self-management programmes have included purely generic information or only condition-specific information, as well as some programmes including carers, especially in the case of Parkinson's Disease. Evidence could only be found on one other programme combining the experience of neurological patients (stroke, Multiple Sclerosis, spinal cord injury) (Hirsche et al. 2011). From the literature, the Hertfordshire model appears unique in including both service users and carers initially, followed by a generic module for service users, and completing with a separate condition-specific module for patients with stroke, Parkinson's Disease and Multiple Sclerosis.

Programme components that appear to contribute to successful application of cognitive management strategies include increasing participant's knowledge of cognitive changes, problemsolving through cognitive challenges, practicing strategies through homework, and conducting the programme in a group format (Shevil and Finlayson 2009).There has been evidence for success of both condition-specific grouping and general grouping (Hirsche et al. 2011). However benefits of condition-specific programme over the generic programme included greater participation and 
completion rates (Cadilhac et al. 2011). This suggests that the design of the Hertfordshire programme with an initial generic module followed by condition specific modules may contribute to the increased participant satisfaction and commitment to completing the programme demonstrated by the low dropout rate of those who started each module.

Delivering the intervention in a group format has been proven to be effective on both patient outcomes and cost-saving. Previous research has found that support of the group was a strong motivator for continued participation and the practice of self-management skills (Nelson et al. 2010). Deliverance in a group format is not only beneficial for increasing self-efficacy through social comparisons but it has also been found that social connections gained through such group interventions are highly valued among this group of patients (Hirsche et al. 2011). One of the aspects of the Hertfordshire programme to be most positively evaluated was sharing experiences and peer support. A concern raised in the previous delivery of self-management in Hertfordshire was the potential distress in being with peers further down the disease trajectory. Because the new programme is offered when people are first referred to the service, the majority of participants are not at this stage and this was not reported as an issue in the revised programme.

Negative effects of self-management education have been found in other studies. Ward et al (2004) report increased dependency and disability after an education programme for progressive neurological disorders such as Multiple Sclerosis, Parkinson's and Huntington's Disease. In an evaluation of a rehabilitation programme for people with Parkinson's Disease, a consistent worsening in all patient measures was found, possibly due to the educational package increasing participants' awareness of future deterioration causing distress, as well as depression because no further input was offered (Wade et al. 2003). However the issue of depression has been addressed in the Hertfordshire programme which has included input from a clinical psychologist to minimise the potential negative effects on self-management. 


\section{Limitations of the programme and process evaluation}

One weakness of this programme is the lack of carer involvement in the latter modules. Although currently the reason for this is a lack of resources, the need to offer something more to carers has been recognised and steps are being taken to ensure that future versions of the programme include carer modules, which may involve delivering in partnership with the voluntary sector to maximise the impact of limited resources. Another potential criticism of the Hertfordshire programme is that it is clinician rather than peer led (Wilson 2008). Although there are benefits to a lay-led programme delivery, a Cochrane review found that there were not any significant effects of lay-led self-management interventions, compared to professionally-led self-management education on improving psychological health, symptoms or health-related quality of life, or significantly altering healthcare use (Foster et al. 2007).

Our process evaluation is limited in terms of sample size and the potential for respondent bias, therefore a more robust independent process and outcome evaluation is required in the future.

\section{The way forward}

Ten years ago a barrier impeding the spread of self-management education was a lack of trained personnel which made self-management courses unavailable in many community and primary care settings (Bodenheimer et al. 2002), this is still a problem even with the current policy focus. Therefore it is very important to prepare clinicians adequately in enabling self-management and increase their knowledge regarding available resources so that service users can be directed towards these (Dickerson et al. 2011). However a greater barrier to programme utilisation was the infrequency with which self-management techniques and referral to such educational programmes became legitimate topics for discussion in primary care consultations (Blakeman et al. 2010). A particular issue for service users with relatively less common conditions such as LTNCs is the lack of clinician expertise within primary care (Lowton and Ballard 2006). Another potential development of 
the Hertfordshire programme would be to adopt a whole systems approach (Kennedy and Rogers 2001) to improve patient information and access to services and promote flexibility in professional response through a patient-centred approach. This would raise awareness with primary care clinicians of self-management needs and strategies in LTNCs.

\section{Conclusion}

Community nurses have an important role in supporting people with LTNCs, however interventions and tools to facilitate self-management with this population are also required. The Hertfordshire self-management programme for people with LTNCs has attempted to address previous problems of self-management interventions for this service user group. The limited evidence we have identified on other LTNC self-management programmes suggests that the Hertfordshire programme is innovative and has the potential to improve self-efficacy and health outcomes for people with Multiple Sclerosis, Parkinson's Disease and stroke. However, there is a need for a robust evaluation to assess whether initial indications are valid, and whether the programme as a relatively resource intensive intervention is cost effective. Such an evaluation would add to the limited evidence base in this area.

\section{Conflict of interest}

There are no conflicts of interest to declare.

\section{$\underline{\text { Key Points }}$}

* There is a need for well designed, long-term neurological condition-specific self-management programmes that covers a wide range of skill teaching using a multidisciplinary approach

* The Hertfordshire Neurological Services programme is innovative and has the potential to improve self-efficacy and health outcomes for people with Multiple Sclerosis, Parkinson's Disease and stroke. 
* From the literature, the Hertfordshire model appears unique in including both service users and carers initially, followed by a generic module for service users, and completing with a separate condition-specific module.

A robust evaluation is required to assess whether initial indications are valid, and whether the programme as a relatively resource intensive intervention is cost effective.

\section{References}

Bandura, A. (1986) Social Foundations of Thought and Action. A Social Cognitive Theory, Prentice Hall, Englewood Cliffs.

Barlow, J., Edwards, R. \& Turner, A. (2009a) The experience of attending a lay-led, chronic disease self-management programme from the perspective of participants with multiple sclerosis. Psychology and Health, 24(10), 1167-1180.

Barlow, J., Turner, A., Edwards, R. \& Gilchrist, M. (2009b) A randomised controlled trial of lay-led self-management for people with multiple sclerosis. Patient Educ Couns, 77, 81-89.

Bernard, S., Aspinal, F., Gridley, K. \& Parker, G. (2008) Integrated policy making in England for adults with long-term neurological conditions (LTNCs): some preliminary findings from a scoping study. International Journal of Integrated Care, 8, 1-8.

Blakeman, T., Bower, P., Reeves, D. \& Chew-Graham, C. (2010) Bringing self-management into clinical view: a qualitative study of long-term condition management in primary care consultations. Chronic Illness, 6, 136-150.

Bodenheimer, T., Lorig, K., Holman, H. \& Grumbach, K. (2002) Patient Self-Management of Chronic Disease in Primary Care. . JAMA, 288(19), 2469-2475. 
Cadilhac, D.A., Hoffmann, S., Kilkenny, M., Lindley, R., Lalor, E., Osbourne, R.H. \& Battersby, M.

(2011) A Phase II Multicentered, Single-Blind, Randomized, Controlled Trial of the Stroke Self-Management Program. Stroke, 42, 1673-1679.

Coster, S. \& Norman, I. (2009) Cochrane reviews of educational and self-management interventions to guide nursing practice: A review. Int J Nurs Stud, 46, 508-528.

Department of Health (2005a) National Service Framework for Long-term Conditions, Department of Health, London.

Department of Health (2005b) Supporting People with Long Term Conditions: An NHS and Social Care Model to supprt local innovation and integration, Department of Health, London.

Department of Health (2009) Long Term Health Conditions 2009. Research Study conducted for the Department of Health, Department of Health, London.

Department of Health (2010) What motivates people to self care, Department of Health, http://www.dh.gov.uk/prod consum dh/groups/dh digitalassets/documents/digitalasset/d h 124052.pdf.

Department of Health (2011) Personalised Care Planning, http://www.dh.gov.uk/prod consum dh/groups/dh digitalassets/documents/digitalasset/d h 124048.pdf, accessed 17.4.12.

Dickerson, J.B., Lee Smith, M., Dowdy, D.M., McKinley, A., Ahn, S. \& Ory, M.G. (2011) Advanced Practice Nurses' Perspectives on the Use of Health Optimization Strategies for Managing Chronic Disease Among Older Adults in Difference Care Settings: Pushing the Boundaries of Self-Management Programs. Geriatric Nursing, 32(6), 429-438.

Foster, G., Taylor, S.J.C., Eldridge, S., Ramsay, J. \& Griffiths, C.J. (2007) Self-management education programmes by lay leaders for people with chronic conditions Cochrane Database Syst Rev, 4(Art. No.: CD005108.). 
Hirsche, R.C., Williams, B., Jones, A. \& Manns, P. (2011) Chronic disease self-management for individuals with stroke, multiple sclerosis and spinal cord injury. Disabil Rehabil, 33(13-14), $1136-1146$.

Jones, B. (2012) Self-management interventions in chronic illness: Considering benefits for fluctuating conditions Health Psychology Update, 21(1), 27-29.

Jones, F., Mandy, A. \& Partridge, C. (2009) Changing self-efficacy in individuals following a first time stroke: preliminary study of a novel self-management intervention Clinical Rehabilitation, 23, 522-533.

Kennedy, A. \& Rogers, A. (2001) Improving self-management skills: a whole systems approach. British Journal of Nursing, 10(11), 734-737.

Leventhal, H., Leventhal, E.A. \& Cameron, L. (2001) Representations, procedures, and affect in illness self-regulation: a perceptual-cognitive model. In Handbook of Health Psychology(Baum, A., Revenson, T. A. and Singer, J. E. eds.) Lawrence Erlbaum Associates Inc, Mahwah, New Jersey, pp. 19-47.

Lorig, K.R. \& Holman, H.R. (2003) Self-Management Education: History, Definition, Outcomes, and Mechanisms. Ann Behav Med, 1, 1-7.

Lowton, K. \& Ballard, K.D. (2006) Adult cystic fibrosis patients' experiences of primary care consultations: a qualitative study. British Journal of General Practice, 56(528), 518-525. Macht, M., Gerlich, C., Ellgring, H., Schradi, M., Rusiñol, A.B., Crespo, M., Prats, A., Viemerö, V., Lankinen, A., Bitti, P.E.R., Candini, L., Spliethoff-Kamminga, N., de Vreugd, J., Simons, G., Smith Pasqualini, M., Thompson, S.B.N., Taba, P., Krikmann, Ü. \& Kanarik, E. (2007) Patient education in Parkinson's disease: Formative evaluation of a standardized programme in seven European countries Patient Educ Couns, 65(2), 245-252.

Mulligan, H., Arps, G., Bancroft, N., Mountfort, R. \& Polkinghorne, A. (2011) 'Living Well with Parkinson's': evaluation of a programme to promote self-management. . J Nurs Healthc Chronic IIIn, 3, 222-233. 
National Audit Office (2005) Reducing Brain Damage: Faster access to better stroke care, NAO, Department of Health.

National Audit Office (2012) Services for people with neurological conditions, NAO, Department of Health.

National Institute for Health and Clinical Excellence (2006) Parkinson's disease: national clinical guideline for diagnosis and managment in primary and secondary care, NICE, London.

Nelson, N., Wong, D. \& Lai, E. (2010) A self-management program for veterans and spouses living with Parkinson's disease J Nurs Healthc Chronic IIIn, 3, 496-503.

Neurological Commissioning Support (2011) Supporting local commissioners to get the right services in the right place at the right time for neurology, NCS, London.

O’Hara, L., Cadbury, H., De Souza, L. \& Ide, L. (2002) Evaluation of the effectiveness of professionally guided self-care for people with multiple sclerosis living in the community: A randomized controlled trial. Clinical Rehabilitation, 16(2), 119-128.

Rae-Grant, A.D., Turner, A.P., Sloan, A., Miller, D., Hunziker, J. \& Haselkorn, J.K. (2011) Selfmanagement in neurological disorders: Systematic review of the literature and potential interventions in multiple sclerosis care J Rehabil Res Dev, 48 (9), 1087-1100.

Shevil, E. \& Finlayson, M. (2009) Process evaluation of a self-management cognitive program for persons with multiple sclerosis Patient Educ Couns, 76, 77-83.

Simons, G., Thompson, S.B.N. \& Smith Pasqualini, M.C. (2006) An innovative education programme for people with Parkinson's disease and their carers. Parkinsonism Relat Disord, 12(8), 478485.

van der Marck, M.A., Kalf, J.G., Sturkenboom, I.H.W.M., Nijkrake, M.J., Munneke, M. \& Bloem, B.R. (2009) Multidisciplinary care for patients with Parkinson's disease. . Parkinsonism Relat Disord, 15S3, S219-S223. 
Wade, D.T., Gage, H., Owen, C., Trend, P., Grossmith, C. \& Kaye, J. (2003) Multidisciplinary rehabilitation for people with Parkinson's disease: a randomised controlled study Journal of Neurology, Neurosurgery \& Psychiatry, 74, 158-162.

Ward, C.D., Turpin, G., Dewey, M.E., Fleming, S., Hurwitz, B., Ratib, S., von Fragstein, M. \& Lymbery, M. (2004) Education for people with progressive neurological conditions can have negative effects: evidence from a randomized controlled trial Clinical Rehabilitation, 18(7), 717-725.

Wilson, P.M. (2001) A policy analysis of the Expert Patient in the United Kingdom: self-care as an expression of pastoral power? Health and Social Care in the Community, 9(3), 134-142.

Wilson, P.M. (2005) Long-term conditions: making sense of the current policy agenda. British Journal of Community Nursing, 10(12), 544-552.

Wilson, P.M. (2008) The UK Expert Patients Program: Lessons learned and implications for cancer survivors' self-care support programs. Journal of Cancer Survivorship, 2, 45-52. 